Kenneth C. Wright, PhD

Murali K. Ravoori, PhD

Katherine A. Dixon, RT

Lin Han, MD, PhD

Sheela P. Singh, PhD

Ping Liu, MS

Sanjay Gupta, MD

Valen E. Johnson, PhD

Zuxing Kan, MD, PhD

Vikas Kundra, MD, PhD

\title{
Perfusion CT Assessment of
} Tissue Hemodynamics Following Hepatic Arterial Infusion of Increasing Doses of Angiotensin II in a Rabbit Liver Tumor Model ${ }^{1}$

Materials and Methods:

Results:

${ }^{1}$ From the Department of Diagnostic Radiology, Section of Interventional Radiology (K.C.W., K.A.D., S.G., Z.K.); Department of Experimental Diagnostic Imaging (M.K.R., L.H., S.P.S., V.K.); and Department of Biostatistics (P.L., V.E.J.), The University of Texas MD Anderson Cancer Center, 1515 Holcombe Blvd, Houston, TX 77030-4009. Received September 17, 2010; revision requested November 30; revision received March 18, 2011; accepted April 4; final version accepted April 20. Supported in part by a grant from the National Cancer Institute (R21 CA123841-010), a grant from the John S. Dunn Research Foundation, and by the National Institutes of Health through MD Anderson's Cancer Center Support Grant CA016672. Address correspondence to K.C.W. (e-mail: kwright@mdanderson.org).

${ }^{\circ}$ RSNA, 2011

Conclusion:
Purpose:

To investigate the effects of increasing doses of angiotensin II on hepatic hemodynamics in the normal rabbit liver and in hepatic VX2 tumors by using dynamic contrast materialenhanced perfusion computed tomography (CT).

This study was approved by the institutional animal care and use committee. Solitary hepatic VX2 tumors were implanted into 12 rabbits. In each animal, perfusion CT of the liver was performed before (at baseline) and after hepatic arterial infusion of varying doses $(0.1-50.0 \mu \mathrm{g} / \mathrm{mL})$ of angiotensin II. Images were acquired continuously for 80 seconds after the start of the intravenous contrast material administration. Blood flow (BF), blood volume (BV), mean transit time (MTT), and capillary permeabilitysurface area product were calculated for the tumor and the adjacent and distant normal liver tissue. Generalized linear mixed models were used to estimate the effects of angiotensin II dose on outcome measures.

Angiotensin II infusion increased contrast enhancement of the tumor and distal liver vessels. Tumor BF increased in a dose-dependent manner after administration of 0.5$25.0 \mu \mathrm{g} / \mathrm{mL}$ angiotensin II, but only the $2.5 \mu \mathrm{g} / \mathrm{mL}$ dose induced a significant increase in tumor BF compared with $\mathrm{BF}$ in the adjacent $(68.0$ vs $26.3 \mathrm{~mL} / \mathrm{min} / 100 \mathrm{~g}, P<.0001)$ and distant $(68.0$ vs $28.3 \mathrm{~mL} / \mathrm{min} / 100 \mathrm{~g}, P=.02)$ normal liver tissue. Tumor BV varied with angiotensin II dose but was greater than the $\mathrm{BV}$ of the adjacent and distant liver tissue at only the $2.5 \mu \mathrm{g} / \mathrm{mL}(4.8 \mathrm{vs} 3.5 \mathrm{~mL} / 100 \mathrm{~g}$ for adjacent liver $[P<.0001], 4.8$ vs $3.3 \mathrm{~mL} / 100 \mathrm{~g}$ for distant liver $[P=.0006])$ and $10.0 \mu \mathrm{g} / \mathrm{mL}(4.9 \mathrm{vs} 4.4 \mathrm{~mL} / 100 \mathrm{~g}$ for adjacent liver $[P=.007], 4.9 \mathrm{vs} 4.3 \mathrm{~mL} / 100 \mathrm{~g}$ for distant liver $[P=.04])$ doses. Tumor MTT was significantly shorter than the adjacent liver tissue MTT at angiotensin II doses of $2.5 \mu \mathrm{g} / \mathrm{mL}(9.7$ vs $15.8 \mathrm{sec}, P=.001)$ and $10.0 \mu \mathrm{g} / \mathrm{mL}$ (5.1 vs 13.2 sec, $P=.007$ ) and significantly shorter than the distant liver tissue MTT at $2.5 \mu \mathrm{g} / \mathrm{mL}$ only $(9.7$ vs $15.3 \mathrm{sec}, P=.0006)$. The capillary permeability-surface area product for the tumor was higher than that for the adjacent liver tissue at the $2.5 \mu \mathrm{g} / \mathrm{mL}$ angiotensin II dose only $(11.5$ vs $8.1 \mathrm{~mL} / \mathrm{min} / 100 \mathrm{~g}, P=.01)$.

Perfusion CT enables a mechanistic understanding of angiotensin II infusion in the liver and derivation of the optimal effective dose. The $2.5 \mu \mathrm{g} / \mathrm{mL}$ angiotensin II dose increases perfusion in hepatic VX2 tumors versus that in adjacent and distant normal liver tissue primarily by constricting normal distal liver vessels and in turn increasing tumor BF and BV.

${ }^{\circ}$ RSNA, 2011 
N umerous vasoactive agents have been evaluated to modify tumor blood flow (BF) in an effort to improve diagnosis and treatment. Initially, the use of pharmacoangiography performed by using various vasoactive drugs was examined in different vascular beds $(1,2)$. Of the vasoconstrictors tested, angiotensin II was shown to be superior for providing diagnostic information, especially in poorly vascularized tumors supplied by small arteries (1).

Subsequently, selective arterial infusion of angiotensin II was investigated as a way to maximize the delivery of chemotherapeutic agents to tumors and minimize the distribution to nontumorous regions. Hepatic arterial infusion of this vasoconstrictor was shown to increase perfusion to both human and experimental liver tumors, but the methods of BF assessment and doses of angiotensin II used varied considerably $(3-7)$. These are important issues because a quantitative reliable method of perfusion assessment is necessary for the objective evaluation of any vascular manipulation procedure and the optimal dose of angiotensin II for pharmacoangiography differs between vascular beds (1).

Dynamic contrast material-enhanced perfusion computed tomography (CT) enables the quantification of various tissue perfusion parameters (8-14). Kinetic modeling is used to analyze the time-attenuation curve generated from a dynamic contrast-enhanced cine CT examination performed at a fixed tissue location after a bolus injection of contrast material. Thus, the BF, blood volume (BV), mean transit time (MTT),

\section{Advances in Knowledge}

- At the appropriate dose, angiotensin II infused into the hepatic artery increased the blood flow and blood volume of experimental liver tumors to levels higher than those of the normal liver tissue.

- Hepatic arterial infusion of angio tensin II at a dose of $2.5 \mu \mathrm{g} / \mathrm{mL}$ appears to be optimal for perfusing rabbit VX2 liver tumors relative to normal liver tissue. and capillary permeability-surface area product of tissue can be calculated. In addition, automated image analysis on a pixel-by-pixel basis can be used to generate parametric images (ie, functional maps) for displaying the perfusion parameters.

Clinically, the most common site for selective arterial infusion therapy is the liver. Since tumor blood vessels commonly lack or have a reduced amount of smooth muscle, we hypothesized that angiotensin II would induce an increase in tumor perfusion in a dose-dependent manner by exerting a direct effect on only the normal liver blood vessels and that there was an optimal dose of this vasoconstrictor that would increase perfusion in the tumor relative to the normal liver. It was further hypothesized that perfusion CT would enable an understanding of the mechanism and optimal dose for the vasoactive effect. The purpose of this study was to investigate the effects of the arterial administration of increasing doses of angiotensin II on hepatic hemodynamics in normal rabbit liver tissue and in hepatic VX2 tumors by using dynamic contrast-enhanced perfusion CT.

\section{Materials and Methods}

All studies were approved by the Institutional Animal Care and Use Committee of The University of Texas MD Anderson Cancer Center. Freshly harvested and prepared VX2 tumor fragments $(0.3 \mathrm{~mL})$ obtained from donor animals were inoculated into the left lobe of the liver in twelve New Zealand white rabbits (Myrtle's Rabbitry, Thompsons Station, Tenn) that weighed 3.5$4.2 \mathrm{~kg}$, as described previously (15). The tumors were allowed to grow for 14-18 days (mean, 15.75 days) and reached a mean size of $19.3 \times 14.6 \mathrm{~mm}$ (range, $13.3 \times 11.5 \mathrm{~mm}$ to $26.9 \times$ $17.6 \mathrm{~mm}$ ) (Table). At the time of imaging, the animals were sedated with an intramuscular injection of buprenorphine (0.15 mg) (Buprenex; Bedford Laboratories, Bedford, Ohio), and anesthesia was induced by using $5 \%$ isoflurane with oxygen, administered at a rate of $1.5 \mathrm{~L} / \mathrm{min}$ through a mask. An endotracheal tube with a three-way stopcock was inserted, and anesthesia was maintained by using $3 \%-5 \%$ isoflurane with oxygen, administered at $1.5 \mathrm{~L} / \mathrm{min}$. A 1-inch 22-gauge catheter (BD Medical, Sandy, Utah) was placed in a marginal ear vein. The right femoral artery was isolated, a 4.0-F introducer sheath (Cook, Bloomington, Ind) was inserted, and 100 IU of heparin per kilogram of body weight was administered. The rabbit was positioned supine on a Lucite board to facilitate accurate positioning and prevent catheter displacement during transport to the scanner.

\section{Perfusion CT Imaging}

The animal was placed in a four-section helical CT scanner (LightSpeed; GE Medical Systems, Milwaukee, Wis). The endotracheal tube was connected to an anesthesia machine with a ventilator and respiratory monitor, and the three-way stopcock side port was connected to a variable positive-pressure oxygen line equipped with a digital manometer. Tubing for the contrast material injection was attached to the ear vein catheter, and a rectal probe was inserted to monitor the heart rate and the oxygen saturation measured with pulse oximetry.

\section{Published online before print 10.1148/radiol.11101868 Content code: GI \\ Radiology 2011; 260:718-726 \\ Abbreviations: \\ $\mathrm{BF}=$ blood flow \\ $\mathrm{BV}=$ blood volume \\ MTT = mean transit time}

\section{Author contributions:}

Guarantors of integrity of entire study, K.C.W., M.K.R., L.H., V.K.; study concepts/study design or data acquisition or data analysis/interpretation, all authors; manuscript drafting or manuscript revision for important intellectual content, all authors; manuscript final version approval, all authors; literature research, K.C.W., M.K.R., S.P.S., S.G., V.K.; experimental studies, K.C.W., M.K.R., K.A.D., L.H., S.P.S., S.G., Z.K., V.K.; statistical analysis, K.C.W., M.K.R., P.L., V.E.J., V.K.; and manuscript editing, K.C.W., M.K.R., S.P.S., S.G., V.E.J., Z.K., V.K.

\section{Funding:}

This research was supported by the National Institutes of Health (grants R21 CA123841-010 and CA016672) and the John S. Dunn Research Foundation.

Potential conflicts of interest are listed at the end of this article. 
The ventilator was activated, and to prevent lung damage, the peak inspiratory pressure was adjusted so that it would not exceed $30 \mathrm{~cm} \mathrm{H}_{2} \mathrm{O}$ (16). When the expired $\mathrm{CO}_{2}$ level was reduced to approximately $50 \%$ of the baseline value, a scout liver scan through the tumor was obtained without contrast material to select the levels for perfusion imaging. Immediately before imaging was started, the ventilator was turned off and positive pressure (20 or $10 \mathrm{~cm}$ $\mathrm{H}_{2} \mathrm{O}$ ) was applied via the three-way stopcock to achieve an inspiratory breath hold. When imaging ended, the positive pressure was removed and the ventilator was reactivated.

After the levels for perfusion imaging were selected and the expired $\mathrm{CO}_{2}$ level was reduced to approximately $40 \%$ of the baseline value, the ventilator was turned off and positive pressure was applied. Imaging was initiated, and $5.0 \mathrm{~mL}$ of contrast material (iodixanol, Visipaque 320; GE Healthcare, Princeton, NJ) was injected at $1.0 \mathrm{~mL} / \mathrm{sec}$. CT scans were acquired continuously for 80 seconds during a constant breath hold at a speed of 0.8 second per rotation. All images were acquired by using a tube voltage of $120 \mathrm{kVp}$, a tube current of $90 \mathrm{~mA}$, a field of view of $25 \mathrm{~cm}$, and a section thickness of $1.25 \mathrm{~mm}$. When imaging ended, the positive pressure was removed.

The animal was then transported to the catheterization laboratory. A 2.8-F microcatheter (EmboCath; BioSphere Medical, Rockland, Mass) was inserted through the femoral artery sheath and manipulated into the proper hepatic artery with fluoroscopic monitoring. Care was taken to minimize the amount of contrast material administered.

The animal was moved to the CT scanner and placed in the same position in which it was placed to obtain the initial scans. Sequential perfusion scans were obtained at least 60 minutes apart to allow the contrast material from the preceding acquisition to clear sufficiently (17). The animal was prepared as before. A nonenhanced CT liver scan was obtained to ensure that the levels through the tumor were similar to those used previously. Once the scan levels were verified and the expired $\mathrm{CO}_{2}$ level was reduced to approximately $40 \%$ of the baseline value, angiotensin II (GenScript USA, Piscataway, NJ) diluted in $10.0 \mathrm{~mL}$ of saline was hand injected over 30 seconds through the arterial catheter, which was then pulled into the aorta or removed. The vasoconstrictor was administered at the following doses: $0.1 \mu \mathrm{g} / \mathrm{mL}$ (four cases), $0.5 \mu \mathrm{g} / \mathrm{mL}$ (three cases), $1.0 \mu \mathrm{g} / \mathrm{mL}$ (four cases), $2.5 \mu \mathrm{g} / \mathrm{mL}$ (three cases), $10.0 \mu \mathrm{g} / \mathrm{mL}$ (three cases), $25.0 \mu \mathrm{g} / \mathrm{mL}$ (three cases), and $50.0 \mu \mathrm{g} / \mathrm{mL}$ (four cases) (Table). Approximately 45 seconds later, perfusion CT imaging was performed by using the technique just described.

Respiration was mechanically arrested during perfusion imaging to ensure that the images were obtained at a fixed tissue location and to eliminate motion artifacts. The expired $\mathrm{CO}_{2}$ level was reduced to similar levels for the baseline and post-angiotensin II perfusion scan acquisitions because hypocapnia has been shown to alter BF to VX2 tumors and the surrounding normal tissue in the brain (11) and in skeletal muscle (17). Initially, a positive pressure of $20 \mathrm{~cm} \mathrm{H}_{2} \mathrm{O}$ was used, but in four animals this resulted in contrast material reflux into the inferior vena cava. Since the accuracy and reproducibility of CT perfusion measurements are also dependent on the contrast material reaching the aorta as a bolus, the CT scans depicting reflux were excluded. Subsequently, the applied positive pressure was reduced to $10 \mathrm{~cm} \mathrm{H}_{2} \mathrm{O}$, which produced the required breath hold without inducing contrast material reflux.

The perfusion images were reconstructed from the raw projection data onto a $512 \times 512$-pixel matrix at 0.4 second intervals by using approximately one-half of the 0.8 -second gantry rotation to improve the temporal sampling $(12,13,17,18)$ before being transferred to an imaging workstation (Advantage Windows; GE Medical Systems) for perfusion analysis. Absolute values of BF, BV, MTT, and capillary permeabilitysurface area product were determined by using CT perfusion software (Body Tumor Perfusion 3.0; GE Healthcare Technologies, Waukesha, Wis). Para- metric map images were created by using the highest spatial resolution pixelby-pixel calculation technique (8).

\section{Liver Enhancement Pattern}

Theoretically, angiotensin II should constrict distal arterial branches in the normal liver, shunting blood from the normal parenchyma to the tumor (1). To determine whether such an effect on the normal liver could be visualized on the cine CT images, two radiologists (V.K., S.G.), each with more than 10 years experience, independently evaluated entire perfusion CT cine image sets in a blinded fashion to determine whether six randomly selected baseline scans could be distinguished from scans that had been acquired after the administration of $2.5 \mu \mathrm{g} / \mathrm{mL}(n=3)$ and $10.0 \mu \mathrm{g} / \mathrm{mL}(n=2)$ doses of angiotensin II. The cine CT images were rated as having homogeneous liver contrast enhancement with visualization of distinct distal vessels (baseline scan) or as having heterogeneous patchy enhancement of the liver with loss of distal vessel definition (post-angiotensin II).

\section{Perfusion Measurements}

Before the perfusion measurements were obtained, the cine CT images and corresponding time-attenuation curves for the aorta, hepatic artery, portal vein, and inferior vena cava were reviewed to ensure scan quality. Cardiac function, which affects perfusion values, was evaluated by measuring the time from the appearance of contrast material in the aorta to the time it reached its peak level. Any scan depicting poor cardiac function (ie, an interval greater than 3 standard deviations from the mean interval calculated from the baseline perfusion scans), motion, or contrast material reflux into the inferior vena cava was excluded.

On the perfusion scans, a cursor indicating a 6-pixel region of interest was placed in the center of the aorta as an arterial input reference $(8,18)$. In addition, at each of the four simultaneously imaged levels, a region of interest was drawn around the entire tumor, around an area of normal liver tissue immediately adjacent to the tumor, and 
in two random locations in the normal liver tissue distant from the tumor (Fig 1). The BF, BV, MTT, and capillary permeability-surface area product were calculated in each of the four hepatic regions of interest. All regions of interest and perfusion measurements were drawn and obtained, respectively, by the same investigator (Z.K.), who had more than 10 years experience in perfusion CT imaging and was blinded to the dose of angiotensin II administered.

\section{Statistical Analyses}

Generalized linear mixed models were used to determine the effect of angiotensin II dose on the BF, BV, MTT, and capillary permeability-surface area product. The primary outcome variable of interest was $\mathrm{BF}$; the other variables were considered to be secondary outcomes. In these models, the measurement type (BF, BV, MTT, or capillary permeabilitysurface area product), angiotensin II dose, tissue location, and dose-location interaction were treated as fixed effects and the animals were treated as random effects. Perfusion values determined at each of the four scan levels were considered repeated measurements. The covariance structure was assumed to be a variance component. That is, a common error component was assumed for each rabbit at each dose, and independent errors were assumed between measurements taken from the same animal at the same dose. Since statistical summary values did not support the assumption of a linear trend of vasoconstrictor effect across doses for the response variables $(\mathrm{BF}, \mathrm{BV}$, MTT, capillary permeability-surface area product), angiotensin II dose was treated as a categorical variable. All multiplicity adjustments were applied only within each response variable so that the type I error applied to the particular measurement only, making 0.185 the overall type I error for all four measures. The method of Dunnett was used to adjust for multiple comparisons. For the liver enhancement pattern classification data (baseline versus post-angiotensin II scan), sensitivity and specificity were calculated and the Fisher exact test was

\begin{tabular}{|c|c|c|c|}
\hline \multicolumn{4}{|c|}{ Angiotensin II Administration Parameters } \\
\hline Animal No. & Time(s) of Perfusion $\mathrm{CT}^{*}$ & Tumor Size (mm) & Angiotensin II Dose $(\mathrm{s})(\mu \mathrm{g} / \mathrm{mL})$ \\
\hline 1 & Day 1 & $18.2 \times 13.3$ & $25.0,10.0$ \\
\hline 2 & Day 1 & $18.7 \times 16.6$ & $25.0,10.0$ \\
\hline 3 & Day 1 & $15.0 \times 12.2$ & $1.0,25.0^{\dagger}$ \\
\hline 4 & Day 1 & $26.9 \times 17.6$ & $50.0,2.5$ \\
\hline 4 & Next day & $26.4 \times 15.8$ & $10.0,2.5,50.0^{\ddagger}$ \\
\hline 5 & Day 1 & $16.5 \times 13.4$ & 2.5 \\
\hline 5 & 3 Days later & $17.0 \times 14.1$ & 50.0 \\
\hline 6 & Day 1 & $16.5 \times 15.6$ & 50.0 \\
\hline 7 & Day 1 & $18.6 \times 13.7$ & 1.0 \\
\hline 8 & Day 1 & $20.3 \times 13.4$ & 1.0 \\
\hline 8 & 2 Days later & $20.7 \times 14.7$ & $0.5,0.1$ \\
\hline 9 & Day 1 & $20.1 \times 17.1$ & 0.5 \\
\hline 9 & 2 Days later & $20.1 \times 13.8$ & 0.1 \\
\hline 10 & Day 1 & $23.1 \times 17.5$ & 0.1 \\
\hline 11 & Day 1 & $16.6 \times 13.8$ & 0.5 \\
\hline 12 & Day 1 & $13.3 \times 11.5$ & $0.1,1.0$ \\
\hline
\end{tabular}

Note.-Tumor sizes represent the largest dimensions measured on the perfusion CT images.

* Day 1 refers to the first day the animal was imaged. Next day, 2 days later, and 3 days later refer to the number of days after day 1 that the second imaging session occurred.

${ }^{\dagger}$ In rabbit 3, the perfusion CT scan obtained after infusion of the $25.0 \mu \mathrm{g} / \mathrm{mL}$ dose of angiotensin II was eliminated because of contrast material reflux into the inferior vena cava.

₹ In rabbit 4, the perfusion CT scan obtained after infusion of the $50.0 \mu \mathrm{g} / \mathrm{mL}$ dose of angiotensin II was eliminated because of contrast material reflux into the inferior vena cava, and the scan obtained after infusion of the $10.0 \mu \mathrm{g} / \mathrm{mL}$ dose was eliminated because of motion.

applied. $P \leq .05$ was considered to indicate statistical significance. All statistical tests were performed by using SAS 9.2 software (SAS Institute, Cary, NC).

\section{Results}

\section{Perfusion CT Images}

No animal exhibited poor cardiac function. Three baseline scans were eliminated because of motion or contrast material reflux into the inferior vena cava. One scan obtained after the administration of a $10.0 \mu \mathrm{g} / \mathrm{mL}$ dose of angiotensin II was eliminated because of motion, and two scans-obtained after the administration of 25.0 and $50.0 \mu \mathrm{g} / \mathrm{mL}$ doses of angiotensin II-were eliminated because of contrast material reflux (Table).

Compared with the baseline CT scans, the post-angiotensin II perfusion scans showed increased contrast enhancement of the tumor, which was greatest at the periphery of the lesion (Fig 2). The normal liver tissue on the baseline scans exhibited homogeneous contrast enhancement with distinct visualization of distal vessels. However, angiotensin II treatment resulted in heterogeneous patchy enhancement of the normal liver tissue that obscured the margins of the distal vessels. This difference in enhancement pattern could be distinguished visually when the images were read in a blinded fashion; both sensitivity and specificity were 100\% (visualization on all six baseline scans and all five post-angiotensin II scans), and the Fisher exact test yielded $P=$ .002. These results suggest that angiotensin II affects predominantly smaller distal vessels.

\section{BF Measurements}

At baseline, the BF (Fig 3) within the tumor was similar to the $\mathrm{BF}$ in the normal liver tissue both adjacent to and distant from the tumor. The tumor BF after administration of $2.5-50.0 \mu \mathrm{g} / \mathrm{mL}$ angiotensin II was significantly greater than the baseline tumor BF, and it peaked at $25.0 \mu \mathrm{g} / \mathrm{mL}$. Tumor BF was unaffected 


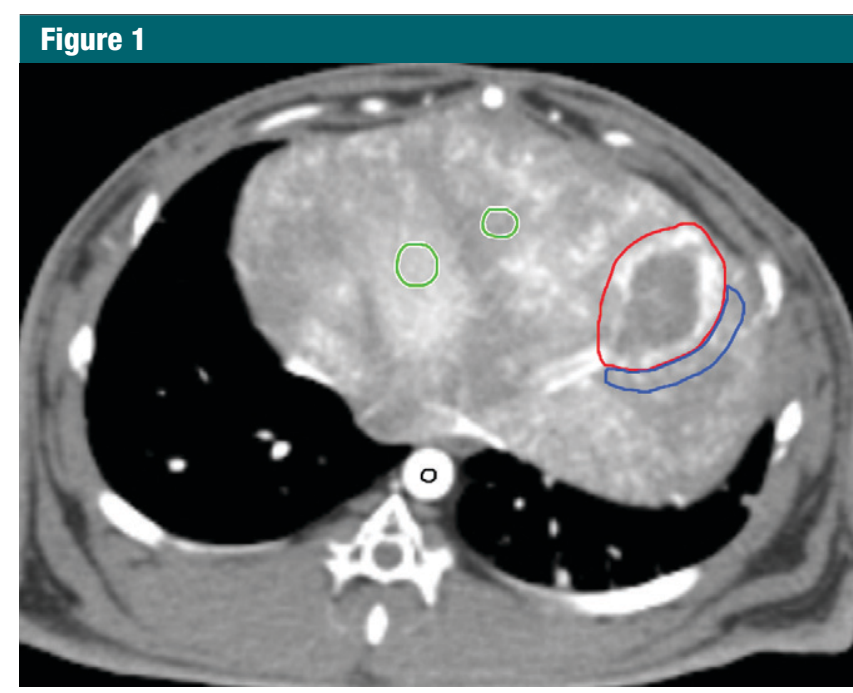

Figure 1: Axial perfusion CT image in rabbit shows placement of regions of interest in center of aorta as arterial input reference (black outline), around entire tumor (red outline), around an area of normal liver tissue immediately adjacent to the tumor (blue outline), and in two random locations in the normal liver tissue distant from the tumor (green outlines).

by the $0.1 \mu \mathrm{g} / \mathrm{mL}$ dose of angiotensin II, whereas doses ranging from 0.5 to $25.0 \mu \mathrm{g} / \mathrm{mL}$ resulted in dose-dependent increases.

The change in tumor BF relative to normal liver tissue BF was dependent on the dose of angiotensin II administered. The BF in the tumor was significantly lower than the BF in the normal adjacent liver tissue at the $1.0 \mu \mathrm{g} / \mathrm{mL}$ angiotensin II dose $(P=.0005,16$ measurements) and significantly greater at doses of $2.5 \mu \mathrm{g} / \mathrm{mL}(P<.0001,12$ measurements), $10.0 \mu \mathrm{g} / \mathrm{mL}(P<.0001$, eight measurements $), 25.0 \mu \mathrm{g} / \mathrm{mL}(P=.04$, eight measurements), and $50.0 \mu \mathrm{g} / \mathrm{mL}$ ( $P=.01,12$ measurements $)$. However, only at the $2.5 \mu \mathrm{g} / \mathrm{mL}$ dose was the tumor BF greater than the BF in the normal distant liver tissue $(P=.02,12$ measurements). Thus, only at an angiotensin II dose of $2.5 \mu \mathrm{g} / \mathrm{mL}$ was the tumor BF increased significantly compared with the BF in the adjacent and distant normal liver tissue.

\section{BV Measurements}

After infusion of angiotensin II, the BV (Fig 4) within the tumor did not change significantly from the baseline value, except at the $25.0 \mu \mathrm{g} / \mathrm{mL}$ dose, where it was increased $(P=.002$, eight measurements). The change in tumor BV relative to normal (adjacent and distant) liver tissue $\mathrm{BV}$ was dependent on the dose of angiotensin II administered. The tumor BV was significantly lower than the adjacent and distant normal liver tissue $\mathrm{BV}$ both at baseline $(P<.0001$ for adjacent liver tissue, $P=.0003$ for distant liver tissue; 36 measurements) and after the administration of $0.5 \mu \mathrm{g} / \mathrm{mL}$ angiotensin II $(P=.004$ for adjacent liver tissue, $P<.0001$ for distant liver; 12 measurements). The tumor BV was significantly lower than only the distant normal liver tissue BV at angiotensin II doses of $0.1 \mu \mathrm{g} / \mathrm{mL}(P=.02,16$ measurements) and $1.0 \mu \mathrm{g} / \mathrm{mL}(P=.007$, 16 measurements). The tumor BV was greater than both the adjacent and the distant normal liver tissue BV at doses of $2.5 \mu \mathrm{g} / \mathrm{mL}(P<.0001$ for adjacent liver tissue, $P=.0006$ for distant liver tissue; 12 measurements) and $10.0 \mu \mathrm{g} / \mathrm{mL}$ $(P=.007$ for adjacent liver tissue, $P=.04$ for distant liver tissue; eight measurements). At the $50.0 \mu \mathrm{g} / \mathrm{mL}$ dose, the tumor BV was significantly greater than the surrounding normal liver tissue $\mathrm{BV}(P=.004,12$ measurements) and similar to the distant normal liver tissue $\mathrm{BV}(P=.65,12$ measurements).

\section{MTT Measurements}

At baseline, the MTT (Fig 5) within the tumor was significantly shorter than the MTT in the adjacent and distant normal liver tissue $(P<.0001,36$ measurements), and the MTT in the surrounding normal liver tissue was significantly shorter than the MTT in the distant normal liver tissue $(P=.001,36$ measurements). Compared with baseline tumor MTTs, tumor MTTs after angiotensin II infusion were similar at the $2.5 \mu \mathrm{g} / \mathrm{mL}$ dose $(P=.06,12$ measurements) and significantly reduced at doses of $10.0 \mu \mathrm{g} / \mathrm{mL}(P=.005$, eight measurements $), 25.0 \mu \mathrm{g} / \mathrm{mL}(P=.006$, eight measurements), and $50.0 \mu \mathrm{g} / \mathrm{mL}$ ( $P=.02,12$ measurements). The tumor MTT was significantly shorter than the adjacent normal liver tissue MTT at angiotensin II doses of $2.5 \mu \mathrm{g} / \mathrm{mL}(P=$ $.001,12$ measurements) and $10.0 \mu \mathrm{g} / \mathrm{mL}$ $(P=.007$, eight measurements $)$ and significantly shorter than the distant normal liver tissue MTT at only the 2.5 $\mu \mathrm{g} / \mathrm{mL}$ dose $(P=.0006,12$ measurements). Thus, a shorter MTT within the tumor relative to the surrounding and distant normal liver tissue was seen at baseline and at an angiotensin II dose of $2.5 \mu \mathrm{g} / \mathrm{mL}$.

\section{Permeability-Surface Area Products}

At baseline, the capillary permeabilitysurface area product (Fig 6) within the tumor was similar to that in the adjacent and distant normal liver tissue; however, the capillary permeability-surface area product in the adjacent normal liver tissue was significantly higher than that in the distant normal liver tissue $(P=.02$, 36 measurements). Compared with the baseline capillary permeability-surface area products, the capillary permeabilitysurface area products in the adjacent and distant normal liver tissue were largely unaffected by angiotensin II infusion. At the $0.5 \mu \mathrm{g} / \mathrm{mL}$ dose of angiotensin II, however, this measurement was significantly higher than the baseline value in the adjacent $(P=.008$, 36 measurements $)$ and distant $(P=$ .0001, 36 measurements) normal liver tissue.

The capillary permeability-surface area product in the tumor was significantly lower than that in the adjacent and distant normal liver tissue when angiotensin II was administered at a dose of $0.5 \mu \mathrm{g} / \mathrm{mL}(P \leq .0001$ for both locations, 12 measurements) and significantly higher than that in the surrounding normal liver tissue when angiotensin II was administered at a dose of $2.5 \mu \mathrm{g} / \mathrm{mL}$ $(P=.01,12$ measurements $)$. Although 

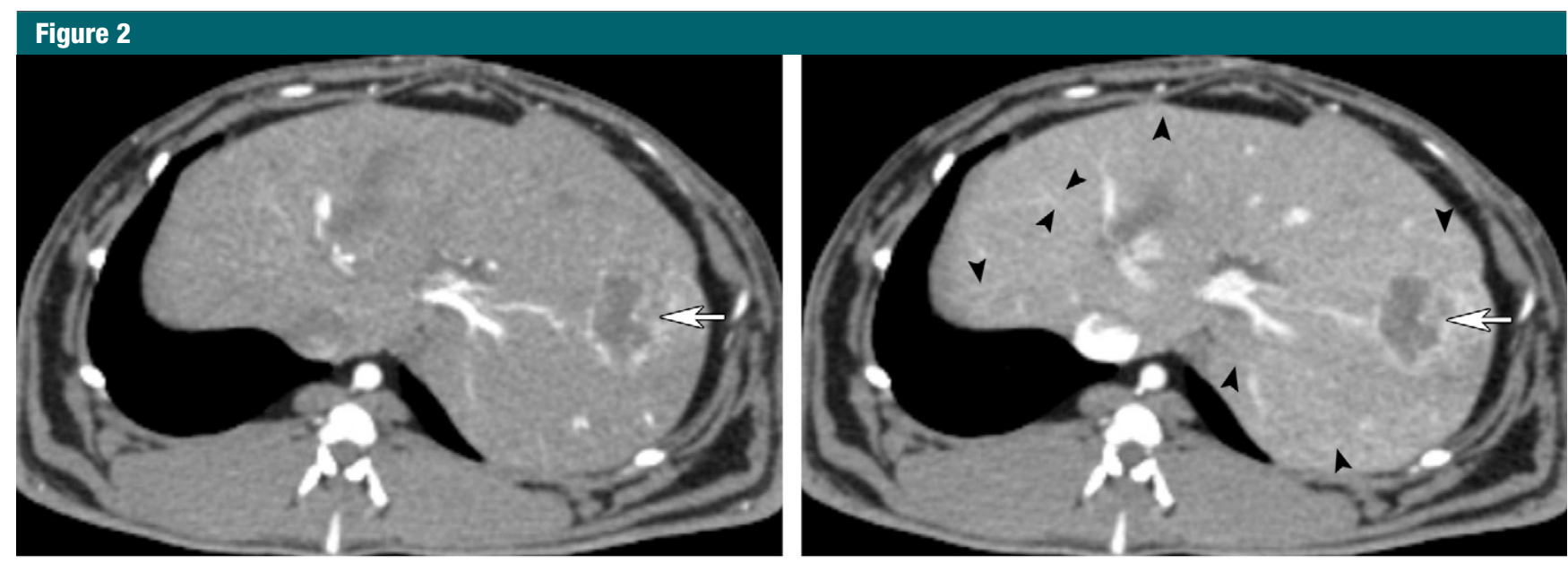

a.

b.
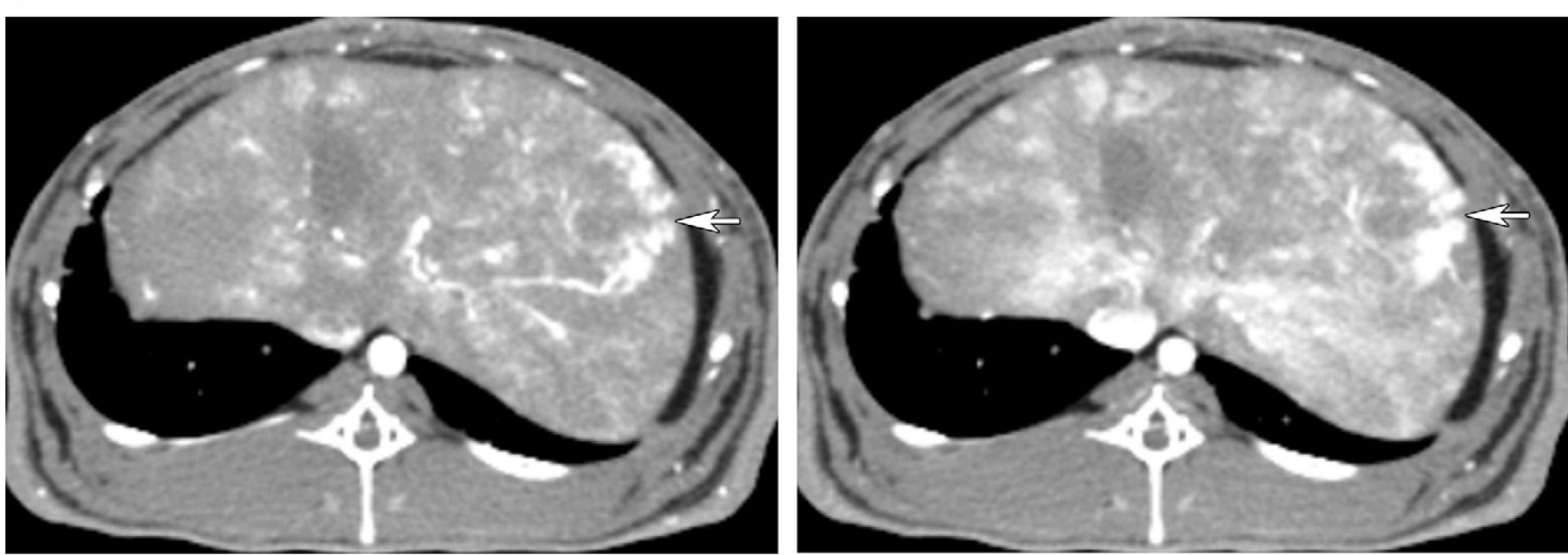

d.

C.

Figure 2: Axial CT images in rabbits show normal liver tissue and VX2 tumor (arrow) (a, b) before angiotensin II administration (animal 11, day 1) and (c, d) after hepatic arterial infusion of a $2.5 \mu \mathrm{g} / \mathrm{mL}$ dose of angiotensin II (animal 4, day 1). Baseline images were obtained 12.0 (a) and 20.0 (b) seconds after start of contrast material injection, and post-angiotensin II perfusion images were obtained 12.2 (c) and 20.2 (d) seconds after start of injection. In c and d, note increased contrast enhancement of tumor, especially its outer rim, and heterogeneous patchy enhancement in normal liver tissue with loss of definition of distal vessels versus homogeneous enhancement with distinct distal vessels (arrowheads) in $\mathbf{a}$ and $\mathbf{b}$.

the capillary permeability-surface area product in the tumor was higher than that in the distant normal liver tissue at the $2.5 \mu \mathrm{g} / \mathrm{mL}$ angiotensin II dose, the difference was not significant $(P=$ .38, 12 measurements). In most cases, the capillary permeability-surface area product was similar in the adjacent and distant normal liver tissue. However, at baseline, the capillary permeabilitysurface area product in the adjacent liver tissue was significantly greater ( $P=.02,36$ measurements $)$, and after the infusion of $0.5 \mu \mathrm{g} / \mathrm{mL}$ angiotensin II, it was significantly lower $(P<.0001$, 36 measurements).

\section{Discussion}

Elevated fluid pressure, as well as mechanical stress generated by tumor cells and their interaction with the extracellular matrix (interstitial stress), causes narrowing and collapse of intratumoral blood vessels (19), which limit the delivery of intraarterially administered therapeutic agents. Since the blood vessels in hepatic tumors, including VX2 cancers, commonly lack smooth muscle $(20,21)$, the arterial infusion of vasoconstricting agents should constrict vessels in the normal liver while leaving the tumor vessels unaffected. This shunts blood from the normal liver parenchyma to the tumor, resulting in increased tumor exposure to transarterially administered therapeutic agents because hepatic tumors derive approximately $90 \%$ of their blood supply from the hepatic artery, unlike normal liver tissue, which receives $70 \%-80 \%$ of its blood supply from the portal vein (22-24).

Angiotensin II is a potent vasoconstrictor that has been shown to enhance the liver tumor-normal liver tissue $\mathrm{BF}$ ratio $(3,4,6)$ and reduce the common hepatic arterial BF (5) after its hepatic arterial administration in patients with primary and metastatic liver tumors. However, the doses of angiotensin II 


\section{Figure 3}

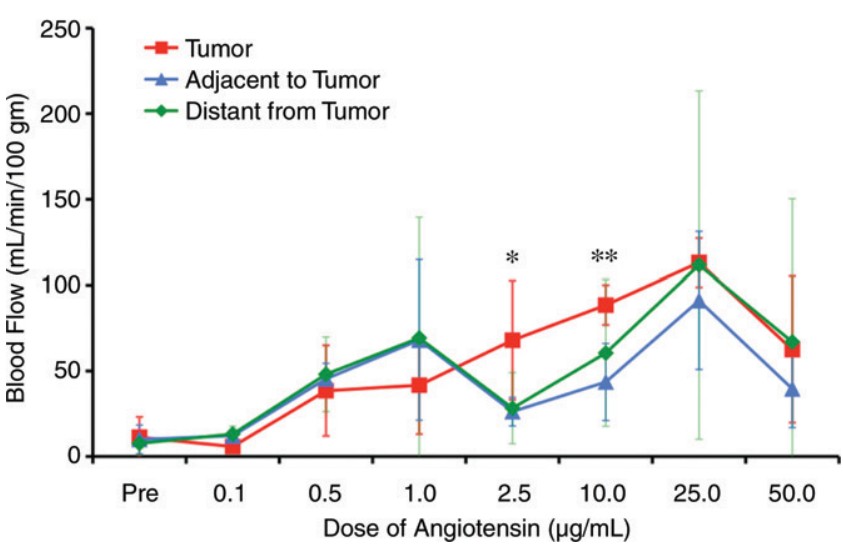

Figure 3: Graph shows mean BF values ( \pm standard deviations) in whole tumor and normal liver tissue immediately adjacent to and distant from tumor, calculated from perfusion CT images obtained before (Pre) and after hepatic arterial infusion of increasing angiotensin II doses. Tumor BF was significantly greater than $\mathrm{BF}$ in normal liver tissue adjacent to $(P<.0001)$ and distant from $(P=.02)$ tumor at $2.5 \mu \mathrm{g} / \mathrm{mL}$ dose (*). Tumor BF was significantly greater than $\mathrm{BF}$ in adjacent normal liver tissue $(P<.0001)$ but similar to that in distant normal liver tissue $(P=.16)$ at $10.0 \mu \mathrm{g} / \mathrm{mL}$ dose $(\star \star)$.

\section{Figure 5}

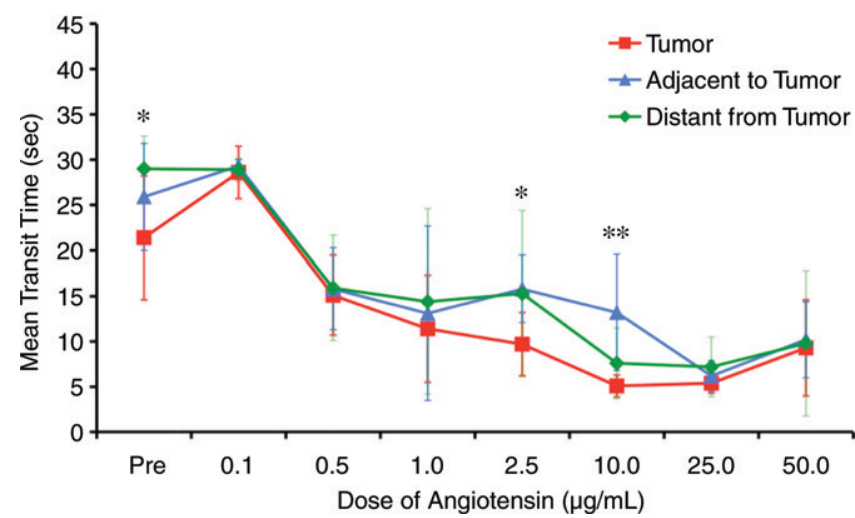

Figure 5: Mean MTTs ( \pm standard deviations) in whole tumor and normal liver tissue immediately adjacent to and distant from tumor, calculated from perfusion CT images obtained before (Pre) and after hepatic arterial infusion of increasing angiotensin II doses. Tumor MTT was significantly shorter than MTT in normal liver tissue adjacent to (before infusion, $P<.0001$; after infusion, $P=.001$ ) and distant from (before infusion, $P<.0001$; after infusion, $P=$ .0006) tumor at $2.5 \mu \mathrm{g} / \mathrm{mL}$ dose of angiotensin II (*). Tumor MTT was significantly shorter than MTT in normal liver tissue adjacent to tumor $(P=.007)$ and similar to MTT in normal liver tissue distant to tumor $(P=.21)$ at $10.0 \mu \mathrm{g} / \mathrm{mL}$ dose $(* \star)$.

administered $(5.0 \mu \mathrm{g} / \mathrm{min}$ for 4 or 45 minutes and $10.0 \mu \mathrm{g} / \mathrm{min}$ for 1.5 or 3-4 minutes) and the modalities used to measure BF (planar single photon emission computed tomography,

\section{Figure 4}

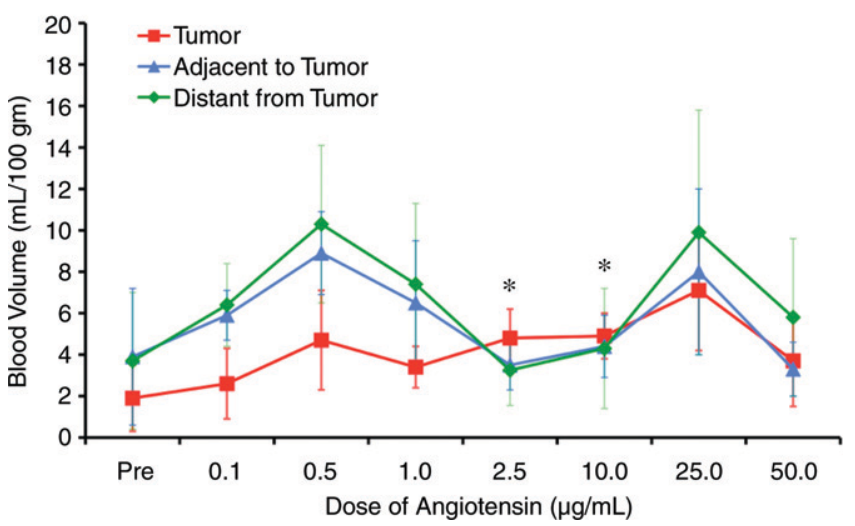

Figure 4: Graph shows mean BV values ( \pm standard deviations) in whole tumor and normal liver tissue immediately adjacent to and distant from tumor, calculated from perfusion CT images obtained before (Pre) and after hepatic arterial infusion of increasing angiotensin II doses. Tumor BV was significantly greater than BV in normal liver tissue adjacent to and distant from tumor at $2.5 \mu \mathrm{g} / \mathrm{mL}(P<.0001$ and $P=.0006$, respectively) and $10.0 \mu \mathrm{g} / \mathrm{mL}(P=.007$ and $P=.04$, respectively) doses (*).

\section{Figure 6}

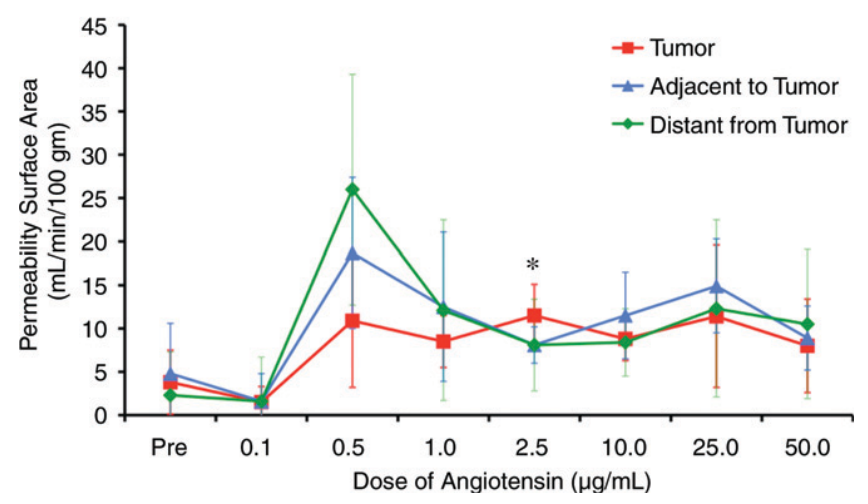

Figure 6: Mean capillary permeability-surface area products ( \pm standard deviations) in whole tumor and normal liver tissue immediately adjacent to and distant from tumor, calculated from perfusion CT images obtained before (Pre) and after hepatic arterial infusion of increasing angiotensin II doses. Capillary permeability-surface area product in tumor was significantly greater than product in normal liver tissue adjacent to tumor $(P=.01)$ and similar to that in normal liver tissue distant from tumor $(P=.38)$ at $2.5 \mu \mathrm{g} / \mathrm{mL}$ dose (*).

the changes in tumor BF, BV, MTT, or capillary permeability-surface area product associated with the administration of angiotensin II, as was done in our study.

Perfusion CT was used in our study because it is a noninvasive imaging modality that enables repeated quantification 
of various parameters of tissue perfusion (8-14). BF, BV, MTT, and capillary permeability-surface area product can be quantified by using kinetic modeling to analyze the time-attenuation curves generated by acquiring a cine CT scan at a fixed tissue location after a bolus injection of contrast material. Sequential perfusion scans were obtained at least 60 minutes apart to allow the contrast material (17) and any angiotensin II $(25,26)$ from the preceding acquisition to clear sufficiently.

The imaging and perfusion parameters measured after angiotensin II administration in our study suggest that the selective arterial infusion of this vasoconstrictor led to increased hepatic VX2 tumor perfusion by inducing a direct effect on blood vessels in the normal liver tissue. Angiotensin II produced heterogeneous patchy contrast enhancement in the normal liver parenchyma that obscured the margins of the distal vessels. These results are similar to the findings reported by Burke et al (6) where heterogeneous distribution of a tissue-trapping BF tracer was seen on PET images after angiotensin II was infused into the hepatic arteries of patients with colorectal liver metastases. The observed spatial heterogeneity is consistent with the vasoconstrictor exerting its effects primarily on smaller distal arterial branches, as has been shown in the kidney (27-29). This explanation is supported by the results reported by Ekelund and Lunderquist (1) showing that after hepatic pharmacoangiography performed with angiotensin II, a marked slowing of $\mathrm{BF}$ through the peripheral hepatic arterial branches was generally seen, to the extent that some small vessels were still filled with contrast material 10-12 seconds after the injection, which occurred 10-20 seconds after the delivery of angiotensin II.

Furthermore, it appears that the drug-induced vasoconstriction of normal distal hepatic arteries shunts blood from the normal liver parenchyma to VX2 tumor vessels, which lack smooth muscle (21) and are thus unresponsive to angiotensin II. The increased $\mathrm{BF}$ alone may have caused passive dilatation and opening of narrowed and collapsed tumor vessels to result in the observed increase in tumor contrast enhancement. The probability that at least a portion of the hepatic VX2 tumor blood vessels are narrowed or collapsed in normal flow conditions was substantiated by the baseline perfusion parameter values in our study, which showed that although the tumor BF was similar to the BF in the surrounding and distant normal liver tissue, both the BV and MTT in the tumor were significantly lower than those in the adjacent and distant normal liver tissue.

In addition, comparable to hepatic arterial pharmacoangiographic parameters $(1,2)$, the perfusion CT parameters after hepatic arterial administration of angiotensin II indicate that there is an optimal dose of this vasoconstrictor that induces the differential effect on tumor versus normal liver tissue vessels. Only at the $2.5 \mu \mathrm{g} / \mathrm{mL}$ dose of angiotensin II were the BF and BV in the tumor significantly higher than those in both the adjacent and the distant normal liver tissue. These results suggest that the $2.5 \mu \mathrm{g} / \mathrm{mL}$ dose of angiotensin II can cause vasoconstriction in the adjacent and distant normal liver that is sufficient to decrease the $\mathrm{BF}$ and $\mathrm{BV}$ in these regions without invoking the hepatic arterial buffer response (30) or inducing hepatic arterial vascular escape (31), which cause arterial vasodilatation in the normal liver parenchyma that is mediated by increased local levels of adenosine and nitric oxide, respectively. The combination of these two hepatic reflex responses has been shown to give the normal liver the unique ability to escape from severe vasoconstrictive influences $(30,31)$; this appears to have occurred at the higher angiotensin II doses, especially $50.0 \mu \mathrm{g} / \mathrm{mL}$, in our study. Furthermore, only at the $2.5 \mu \mathrm{g} / \mathrm{mL}$ dose was the capillary permeabilitysurface area product of the tumor significantly higher than that of the surrounding normal liver tissue. However, the tumor MTT at this dose, similar to the baseline MTT, was significantly shorter than the MTT in the adjacent and distant normal liver tissue. To our knowledge, these findings have not been reported previously because no previously published studies have involved the use of perfusion CT to assess liver hemodynamics after hepatic arterial infusion of angiotensin II. Collectively, the perfusion results imply that higher levels of therapeutic agent may reach and cross the liver tumor blood vessels after hepatic arterial infusion of a $2.5 \mu \mathrm{g} / \mathrm{mL}$ dose of angiotensin II. However, further research is needed to confirm that the observed perfusion changes are clinically important for enhanced delivery of therapeutic agents into the hepatic artery immediately after angiotensin II administration. A potential limitation of our study was the relatively small number of times each dose of angiotensin II was evaluated. However, significant results were obtained.

Practical application: The reported data demonstrate that perfusion CT can be used to assess the effects of intraarterially administered vasoactive drugs (eg, vasoconstrictors such as angiotensin II) on tissue perfusion parameters and identify the optimal effective dose. The results suggest that arterial infusion of angiotensin II increased hepatic VX2 tumor perfusion by means of direct constriction of the distal vessels in the normal liver parenchyma, which in turn shunted blood into the passively responsive tumor vessels, primarily increasing the $\mathrm{BF}$ and $\mathrm{BV}$ in the tumor relative to the normal liver tissue. Furthermore, an angiotensin II dose of $2.5 \mu \mathrm{g} / \mathrm{mL}$ appears to be optimal for directing perfusion to $\mathrm{VX} 2$ tumors (versus to normal liver tissue), which may increase the transarterial delivery of therapeutic agents to the tumor.

Disclosures of Potential Conflicts of Interest: K.C.W. No potential conflicts of interest to dis close. M.K.R. No potential conflicts of interest to disclose. K.A.D. No potential conflicts of interest to disclose. L.H. No potential conflicts of interest to disclose. S.P.S. No potential conflicts of interest to disclose. P.L. No potential conflicts of interest to disclose. S.G. No potential conflicts of interest to disclose. V.E.J. No potential conflicts of interest to disclose. Z.K. No potential conflicts of interest to disclose. V.K. No potential conflicts of interest to disclose. 


\section{References}

1. Ekelund L, Lunderquist A. Pharmacoangiography with angiotensin. Radiology 1974; $110(3): 533-540$.

2. Ekelund L, Laurin S, Lunderquist A. Comparison of a vasoconstrictor and a vasodilator in pharmacoangiography of bone and soft-tissue tumors. Radiology 1977;122(1):95-99.

3. Sasaki Y, Imaoka S, Hasegawa Y, et al. Changes in distribution of hepatic blood flow induced by intra-arterial infusion of angiotensin II in human hepatic cancer. Cancer 1985;55(2):311-316.

4. Goldberg JA, Thomson JA, Bradnam MS, et al. Angiotensin II as a potential method of targeting cytotoxic-loaded microspheres in patients with colorectal liver metastases. $\mathrm{Br} \mathrm{J}$ Cancer 1991;64(1):114-119.

5. Leen E, Angerson WJ, Warren HW, et al. Duplex/colour Doppler sonography: measurement of changes in hepatic arterial haemodynamics following intra-arterial angiotensin II infusion. Br J Cancer 1993;67(6): 1381-1384.

6. Burke D, Davies MM, Zweit J, et al. Continuous angiotensin II infusion increases tumour: normal blood flow ratio in colo-rectal liver metastases. Br J Cancer 2001;85(11): 1640-1645.

7. Hemingway DM, Cooke TG, Chang D, Grime SJ, Jenkins SA. The effects of intra-arterial vasoconstrictors on the distribution of a radiolabelled low molecular weight marker in an experimental model of liver tumour. $\mathrm{Br} \mathrm{J}$ Cancer 1991;63(4):495-498.

8. Lee TY. Functional CT: physiological models. Trends Biotechnol 2002;20(8):S3-S10.

9. Miles KA, Griffiths MR. Perfusion CT: a worthwhile enhancement? Br J Radiol 2003; 76(904):220-231.

10. Miles KA, Charnsangavej C, Lee FT, Fishman EK, Horton K, Lee TY. Application of CT in the investigation of angiogenesis in oncology. Acad Radiol 2000;7(10):840-850.

11. Cenic A, Nabavi DG, Craen RA, Gelb AW, Lee TY. A CT method to measure hemody- namics in brain tumors: validation and application of cerebral blood flow maps. AJNR Am J Neuroradiol 2000;21(3):462-470.

12. Purdie TG, Henderson E, Lee TY. Func tional CT imaging of angiogenesis in rabbit VX2 soft-tissue tumour. Phys Med Biol 2001;46(12):3161-3175.

13. Hashimoto K, Murakami T, Dono K, et al. Quantitative tissue blood flow measurement of the liver parenchyma: comparison between xenon CT and perfusion CT. Dig Dis Sci 2007;52(4):943-949.

14. Meijerink MR, van Waesberghe JH, van Schaik C, et al. Perfusion CT and US of colorectal cancer liver metastases: a correlative study of two dynamic imaging modalities. Ultrasound Med Biol 2010;36(10): 1626-1636.

15. Geschwind JF, Ko YH, Torbenson MS, Magee C, Pedersen PL. Novel therapy for liver cancer: direct intraarterial injection of a potent inhibitor of ATP production. Cancer Res 2002;62(14):3909-3913.

16. Hartsfield SM. Airway management and ven tilation. In: Tranquilli WJ, Thurmon JC, Grimm KA, eds. Lumb \& Jones' veterinary anesthesia and analgesia. 4th ed. Ames, Iowa: Blackwell, 2007; 514.

17. Purdie TG, Lee TY. Carbon dioxide reactivity of computed tomography functional parameters in rabbit VX2 soft tissue tumour. Phys Med Biol 2003;48(7):849-860.

18. Kan Z, Kobayashi S, Phongkitkarun S, Charnsangavej C. Functional CT quantification of tumor perfusion after transhepatic arterial embolization in a rat model. Radiology 2005;237(1):144-150.

19. Sarntinoranont M, Rooney F, Ferrari M. Interstitial stress and fluid pressure within a growing tumor. Ann Biomed Eng 2003;31(3): 327-335.

20. Ashraf S, Loizidou M, Crowe R, Turmaine M, Taylor I, Burnstock G. Blood vessels in liver metastases from both sarcoma and carcinoma lack perivascular innervation and smooth muscle cells. Clin Exp Metastasis 1997;15(5):484-498
21. Zlotecki R, Ullrich K, Ensminger W. Hepatic tumor vascularity in the rabbit VX2 tumor model [abstr]. Proc AACR 1986;27:406.

22. Breedis C, Young G. The blood supply of neoplasms in the liver. Am J Pathol 1954; 30(5):969-977.

23. Bhattacharya S, Davidson B, Dhillon AP. Blood supply of early hepatocellular carcinoma. Semin Liver Dis 1995;15(4):390-401.

24. Kan Z, Ivancev K, Lunderquist A, et al. In vivo microscopy of hepatic tumors in animal models: a dynamic investigation of blood supply to hepatic metastases. Radiology 1993; 187(3):621-626.

25. Chapman BJ, Brooks DP, Munday KA. Halflife of angiotensin II in the conscious and barbiturate-anaesthetized rat. Br J Anaesth 1980;52(4):389-393.

26. Magness RR, Cox K, Rosenfeld CR, Gant NF. Angiotensin II metabolic clearance rate and pressor responses in nonpregnant and pregnant women. Am J Obstet Gynecol 1994; 171(3):668-679.

27. Elkin M, Meng CH. The effects of angiotensin on renal vascularity in dogs. Am Roentgenol Radium Ther Nucl Med 1966; 98(4):927-934.

28. Finberg JPM, Peart WS. The effect of angio tensin, noradrenaline and vasopressin on blood flow distribution in the rat kidney. J Physiol (Paris) 1972;220(1):229-242.

29. Krahé P, Hofbauer KG, Gross F. Effects of angiotensin infusion on the isolated rabbit kidney. Proc Soc Exp Biol Med 1971; 137(4):1324-1327.

30. Lautt WW. Regulatory processes interacting to maintain hepatic blood flow constancy: vascular compliance, hepatic arterial buffer response, hepatorenal reflex, liver regeneration, escape from vasoconstriction. Hepatol Res 2007;37(11):891-903.

31. Ming Z, Han C, Lautt WW. Nitric oxide mediates hepatic arterial vascular escape from norepinephrine-induced constriction. Am J Physiol 1999;277(6 Pt 1):G1200-G1206. 